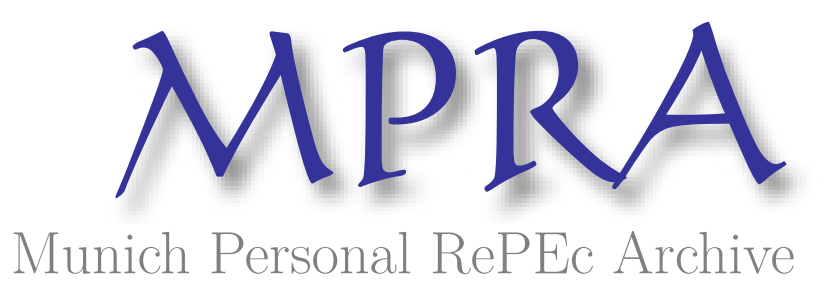

\title{
Inequality aversion causes equal or unequal division in alternating-offer bargaining
}

Kohler, Stefan

Institute for Social Medicine, Epidemiology and Health Economics, Charité University Medical Center, Free University and Humboldt University of Berlin, Germany

6 July 2013

Online at https://mpra.ub.uni-muenchen.de/40764/

MPRA Paper No. 40764, posted 07 Jul 2013 18:32 UTC 


\title{
Inequality aversion causes equal or unequal division in alternating-offer bargaining
}

\author{
Stefan Kohler*
}

\begin{abstract}
This note presents a solution to Rubinstein (1982)'s open-ended, alternating-offer bargaining problem for two equally patient bargainers that exhibit similar degrees of inequality aversion. Inequality-averse bargainers may perceive envy if being worse off and guilt if being better off, but they still reach agreement in the first period under complete information. If the perceived guilt is strong, then the inequality-averse bargainers split the bargaining surplus equally regardless of their degree of envy. If guilt is weak, then the agreed split is tilted away from the Rubinstein division towards a more unequal split. Envy and weak guilt have opposite effects on the bargaining outcome, and envy has a greater marginal impact than weak guilt. Similarly inequality-averse bargainers agree on the Rubinstein division if the strength of envy equals the discounted strength of guilt. As both bargainers sensation of inequality aversion diminishes, the bargaining outcome converges to the Rubinstein division.
\end{abstract}

Keywords: alternating offers, bargaining, bargaining power, behavioral economics, envy, equity, fairness, guilt, negotiation, social preferences

JEL classifications: C72, C78, D03, D31, D63, D64

\section{Introduction}

Some social preferences assume inequality aversion, a utility loss caused by receiving the smaller or the larger share (Bolton \& Ockenfels 2000; Fehr \& Schmidt 1999; Kohler 2011; Tan $\&$ Bolle 2006). Inequality aversion, and variations therein, can explain main features of experimental behavior observed across different bargaining games and sociocultural contexts (e.g., Barr et al. 2009; Bellemare et al. 2008; De Bruyn \& Bolton 2008; Goeree \& Holt 2000; Kohler 2013b). However, theoretical and empirical work has focused on the study of inequality aversion in finite horizon bargaining.

This note adds a small theoretical contribution to the existing literature by presenting a solution to Rubinstein (1982)'s open-ended, alternating-offer bargaining problem for two equally patient bargainers that exhibit similar degrees of inequality aversion. Since inequality aversion diminishes the utility from unequal partitions, more equal divisions and disagreement, in which case both bargainers receive nothing in the failed bargaining round, become more attractive in Rubinstein (1982)'s bargaining problem. Thus, some previously incredible threats

*July 6, 2013. Institute for Social Medicine, Epidemiology and Health Economics, Charité University Medical Center, Free University and Humboldt University of Berlin, Germany; Email: stefan.kohler@charite.de, Homepage: http:/ / epidemiologie.charite.de. I have benefited from helpful and constructive comments by Karl Schlag, Pascal Courty, Simon Gächter, Jordi Brandts and anonymous reviewers. I gratefully acknowledge the financial support provided by the European University Institute and the German Academic Exchange Service at an early stage of this research. 
to reject uneven partitions become credible for inequality-averse bargainers whose decisionmaking is affected by the fairness of their presently realizable outcome and the fairness of their outside option, i.e., the payoff distribution realized in case of disagreement.

Envy and guilt, the two components of inequality aversions, influence the bargaining partition in opposing directions, but allocations under which the disadvantaged party feels envy do not occur throughout the bargaining if guilt is high. Hence, the relative strength of guilt in comparison to bargaining parties' self-interest impacts the bargaining outcome in two ways: High guilt triggers an equal division because the bargainers' utility decreases when receiving more than half. Low guilt diminishes the marginal utility of income, but preserves its positive marginal utility. Own low guilt, ceteris paribus, weakens the own bargaining position. Roth (1985) showed a similar influence of risk aversion that also works to a bargainer's disadvantage within each bargaining period. Overall, the same degree of low guilt in both bargainers helps the proposing bargainer to take a larger share than predicted by Rubinstein. The paradox as to why feeling guilty about a larger share can result in a more unequal division than the bargaining of self-interested parties is driven by the weakened bargaining position of the disadvantaged bargainer. The disadvantaged bargainer compares accepting a share smaller than half to proposing a share larger than half in the subsequent period, the utility of which is diminished by guilt. As low guilt maintains a positive marginal utility of income, the proposing bargainer exploits the lowered value of the accepting bargainer's outside option by increasing his demand. Low guilt has the opposite effects of envy. Envy, ceteris paribus, reinforces the bargaining position of a bargainer. If the two bargainers are only similarly envious, then the bargaining outcome departs from the Rubinstein division converging toward an equal split. If no bargainer is averse to inequality then bargaining proceeds as predicted by Rubinstein.

Section 2 reviews related literature. Section 3 introduces the alternating-offer bargaining problem with inequality-averse bargainers. I derive the bargaining outcome in section 4 . Section 5 discusses the equilibrium outcome and concludes.

\section{Related literature}

Various research suggests that at least some people show regard for others, which includes aspects of envy (e.g., Camerer 2003; Herreiner \& Puppe 2009; Smith 2008; Zwick et al. 1992). The empirical evidence of guilt in addition to envy in bargaining experiments is mixed. Estimating average inequality aversion as introduced by Bolton \& Ockenfels (2000) in a structural model of bounded rationality based on data from an ultimatum game field experiment in Zimbabwe, Kohler (2013b) finds significant inequality aversion and self-interest in three different areas studied. Overall, the data was better explained by a model of guilt and envy, i.e., symmetric inequality aversion, than by a model of envy, i.e., asymmetric inequality aversion (Kohler 2008). Also De Bruyn \& Bolton (2008) discuss that symmetric inequality aversion may statistically improve the fit of different experimental bargaining data in a meta-analyses with the Bolton \& Ockenfels (2000) model of inequality aversion, but they preferred an asymmetric specification of the model that only captures envy to predict bargaining behavior because, inter alia, it provided better out-of-sample forecasts for their finite horizon bargaining games.

Alternating-offer bargaining between envious bargainers with player-specific preferences has previously been studied in an infinite horizon game with complete information and in 
a finite horizon game with incomplete information (Kohler 2012b, 2013a). Infinite horizon alternating-offer bargaining between similar, merely guilt-perceiving bargainers has been studied by Kohler (2012a). All three of these earlier studies assume versions of the Fehr \& Schmidt (1999) model of inequality aversion. So does the paper at hand, which considers similar bargainers that can experience envy and guilt in the Rubinstein bargaining problem. I generalizes Kohler (2012a) and my findings complement Mauleon \& Vannetelbosch (2013), who, like Kohler (2012b), study relative concerns and delay in alternating-offer bargaining with private information. Assuming complete information and that both players had relative concerns captured by a special case of Fehr \& Schmidt (1999)'s model of inequality aversion, Mauleon \& Vannetelbosch derive that an increase of the first mover's envy can decreases the second mover's equilibrium payoff and that an increase of the second mover's guilt can increase the payoff of the first mover if the difference in discounting is sufficient. Inequality aversion has also been studied in bargaining games in which unanimity was not required. In line with the present findings, Montero (2007) establishes that the equilibrium payoff division can be more unequal despite inequality-averse bargaining parties.

The inequality aversion model studied consists of envy and guilt. Guilt shares some features with altruism because a guilt perceiving person feels altruistic towards others until the advantageous situation disappears (see, Kohler 2011). Altruism may be beneficial when there is competition for bargaining partners. It may be detrimental if bargainers discriminate towards whom they feel altruistic (Montero 2008).

\section{Bargaining model}

Two bargainers $i, j \in\{b, s\}$, called the seller and the buyer, have to reach an agreement on the partition of a surplus of size one which depreciates after any disagreement. Bargaining takes place at periods of time $t=1,2, \ldots, T$. Depreciation is modeled by assigning a common discount factor $\delta=\delta_{b} \equiv \delta_{s}<1$ to the two bargainers. By naming a partition $p_{t} \in(0,1]$ in odd periods, the seller demands share $p_{t}$ and offers share $\left(1-p_{t}\right)$ that the buyer can either accept or reject. In even periods, the buyer proposes a partition $p_{t}$ to the seller that he can either accept or reject. If a partition is accepted, the game ends in period $T$. This bargaining outcome is denoted $\left(p_{T}, T\right)$.

Assuming complete information in this bargaining problem, Rubinstein (1982) has shown the existence of a unique subgame perfect equilibrium (SPE) under generic preference assumptions. ${ }^{1}$ For preferences $u_{i}\left(x_{i}\right)=x_{i}$, where utility is derived from one's own payoff $x_{i}$, Rubinstein derived an explicit solution in which the seller proposes and the buyer accepts partition $p^{*}=\frac{1}{1+\delta} \in[0.5,1)$ in period 1 . The equilibrium outcome is supported by the bargainers' similar strategies: Bargainer $i$ always demands the equilibrium share $p^{*}$, when it is his turn to make a proposal; otherwise accepts any share equal or greater than $\delta p^{*}$ and refuses any smaller share. The demand of $p^{*}$ is the highest share that is accepted by the other bargainer $j$.

${ }^{1}$ (i) 'pie' is desirable, (ii) 'time' is valuable, (iii) continuity, (vi) stationarity, i.e., the preference of $(\hat{p}, t)$ over $(\tilde{p}, t+1)$ is independent of $t$, and (v) the larger the portion, the more 'compensation' a player needs for a delay of one period to be immaterial to him. Strategies are said to constitute a SPE if, in every subgame, the strategies relating to that subgame form a Nash equilibrium. In a SPE, a bargainer will agree to a proposal if it offers at least as much as he will obtain in the future given the strategies of both bargainers. Rubinstein (1982) states the precise definitions. 
Bargainer $i$ cannot gain by asking for a lower share, for it too will be accepted. Stipulating a higher (and rejected) share and waiting to accept bargainer $j^{\prime}$ s counteroffer in the next period hurts bargainer $i$ as $\delta\left(1-p^{*}\right)=\delta^{2} p^{*}<p^{*}$.

This study builds on Rubinstein's framework and investigates the strategic behavior of bargainers who care, to some extent, about relative as well as absolute payoff in the bargaining process described. Relative payoff hereby means bargainers compare their own benefit $x_{i}$ from accepting a certain partition to the benefit of the other bargainer $x_{j}$, and put common weight $\alpha \geq 0$ on the difference whenever their own benefit is lower and common weight $\beta \in[0,1)$, where $\alpha \geq \beta$, on the difference whenever their own benefit is higher. These relative concerns are interpreted as envy and guilt. Explicitly, I assume that the utility function of the bargainers is given by:

$$
u_{i}\left(x_{i}, x_{j}\right)=x_{i}-\alpha \max \left\{x_{j}-x_{i}, 0\right\}-\beta \max \left\{x_{i}-x_{j}, 0\right\}
$$

These preferences of inequality aversion were originally put forward in Fehr \& Schmidt (1999) and extended by altruism in Kohler (2011). Inequality aversion consistently predicts a rich set of stylized experimental behavior (see, e.g., Cooper \& Kagel n.d.; Fehr \& Schmidt 1999). The inequality aversion preferences violate some of Rubinstein's preference assumptions, but a unique bargaining outcome continues to exist if $\beta \neq 0.5$. Throughout, $u_{s}\left(p_{t}\right):=u_{s}\left(p_{t}, 1-p_{t}\right)$ denotes the seller's utility and $u_{b}\left(p_{t}\right):=u_{b}\left(1-p_{t}, p_{t}\right)$ the corresponding buyer's utility if a proposed partition $p_{t}$ is accepted in period $t$.

\section{Subgame perfect equilibrium}

Proposition 1. The alternating-offer bargaining problem with similarly inequality-averse and discounting bargainers has a unique SPE if $\beta \neq 0.5$. If guilt is high, i.e., $\beta \geq 0.5$, then the seller immediately receives half of the surplus. If guilt is low, i.e., $\beta<0.5$, then the seller immediately receives:

$$
p^{*}=\frac{1+\alpha-\beta \delta}{1+2 \alpha+\delta(1-2 \beta)}
$$

The proof of proposition 1 is divided in two parts. For low guilt $\beta<0.5$, the first part of the proof is based on Shaked \& Sutton (1984) who applied backwards induction in a truncation of the infinite horizon game: The beginning of the infinite horizon game is equal to its subgame in the third round, should it be reached. In odd periods, the seller is proposing and then the bargainers alternate in making subsequent offers until an agreement is reached. For high guilt $\beta \geq 0.5$, the argument of second part of the proof is based on the negative marginal utility of own income.

Proof. Suppose the above strategies induce a backwards induction outcome $\left(p^{*}, 1\right)$ of the game as a whole. It is possible to use the partition $p^{*}$ in the subgame, which starts in the third period, assuming it was reached, and, then, to work back to the first period. In the backward induction outcome of the whole game, the seller will propose $p_{1}=\pi\left(p_{3}\right)$ in period 1 and the buyer will accept. If $\pi$ is a monotone function, then the equilibrium partition is uniquely defined by $p^{*}=\pi\left(p^{*}\right)$. In order to determine $\pi$, the periods in which inequality aversion influences the bargainers' decisions need to be identified. For now, assume the payoff distribution favors 
the proposing bargainer each time such that the proposer can always obtain at least half of the surplus if $\beta<0.5$, i.e., $p_{1} \geq 0.5, p_{2} \leq 0.5, p_{3} \geq 0.5$. This assumption is shown to be valid after deriving the equilibrium outcome.

The period 3 subgame begins with a successful proposal $p_{3} \in[0.5,1]$ by a guilt-perceiving seller that feels envy if a disadvantageous partition $p_{2} \leq 0.5$ was agreed. Consequently, the lowest share $p_{2}=\left(\alpha_{s}+\delta_{s}\left(\beta_{s}+p_{3}\left(1-2 \beta_{s}\right)\right)\right)\left(1+2 \alpha_{s}\right)^{-1}$ that is accepted by the seller in period 2 gives him the equivalent of his outside option, the discounted period 3 utility. Similarly, the highest share $p_{1}=\left(\left(1+\alpha_{b}\right)-\delta_{b}\left(1-\beta_{b}-p_{2}\left(1-2 \beta_{b}\right)\right)\right)\left(1+2 \alpha_{b}\right)^{-1}$ that is accepted by the buyer in period 1 gives him the equivalent of his outside option, the discounted period 2 utility. Indifferent bargainers are assumed to accept the proposed partition. As $u_{b}\left(p_{2}\right) \geq \delta u_{b}\left(p_{3}\right)$ and $u_{s}\left(p_{1}\right) \geq \delta u_{s}\left(p_{2}\right)$, the buyer and seller prefer proposing the agreeable partitions that maximize their utility to disagreement with the subsequent counteroffer.

Since the game in period 3 is identical to the game in period 1, the unique fixed point $p^{*}:=p_{1}\left(p_{3}\right) \equiv p_{3}$ defines the equilibrium partition:

$$
p^{*}=\frac{\left(1+\alpha_{b}\right)\left(1+2 \alpha_{s}\right)-\delta_{b}\left(1+\alpha_{s}\right)+\delta_{b}\left(\beta_{b}+\beta_{s} \delta_{s}\left(1-2 \beta_{b}\right)\right)}{\left(1+2 \alpha_{b}\right)\left(1+2 \alpha_{s}\right)-\delta_{b} \delta_{s}\left(1-2 \beta_{b}\right)\left(1-2 \beta_{s}\right)}=\frac{1+\alpha-\beta \delta}{1+2 \alpha+\delta(1-2 \beta)}
$$

As only $p_{2}$ and $p_{1}$ maximize the utility of the bargainer proposing the partition, there is no other SPE.

The advantage of the proposing bargainer on the equilibrium path requires $p_{2} \leq 0.5$, implied by the infimum of $p^{*}$ and the supremum of $p_{2}\left(p^{*}\right)$ : The partial derivatives of the equilibrium partition $p^{*}$ with respect to envy $\partial p^{*} / \partial \alpha<0$, guilt $\partial p^{*} / \partial \beta \geq 0$ and the discount factor $\partial p^{*} / \partial \delta<0$ are negative, weakly positive and negative, respectively. Hence, the infimum of $p^{*}$ is $\lim _{(\alpha, \beta, \delta) \rightarrow(\infty, 0,1)} p^{*}$ which evaluates to 0.5 . Similarly, as $\partial p_{2} / \partial \alpha>0, \partial p_{2} / \partial \beta \leq 0$ and $\partial p_{2} / \partial \delta>0$, the supremum of $p_{2}\left(p^{*}\right)$ is $\lim _{(\alpha, \beta, \delta) \rightarrow(\infty, 0,1)} p_{2}$ which also evaluates to 0.5 . Therefore, the assumed advantage of the proposing bargainer to receive half or more of the surplus on the equilibrium path is true. The partial derivatives are derived in appendix 6.1.

If $\beta>0.5$, then $u_{s}(0.5)>u_{s}(0.5+\epsilon)$. Thus, the equal division is weakly preferred to any advantageous share by the seller in any period $t$. Further, as $u_{b}(0.5)<u_{b}(0.5-\epsilon)$, the equal division is preferred by the buyer receiving the disadvantageous share in period $t$. By the same arguments the buyer also weakly prefers the equal division to any advantageous share and the seller prefers redistribution of the surplus until its equal division is agreed. Thus, $p^{*}=0.5$ is the only equilibrium partition. Indifferent bargainers for which $\beta=0.5$ are assumed to choose the equal division, but in this case the SPE is not unique. As bargainers discount it is immediately asked and agreed.

\section{Discussion and conclusion}

Bargainers may incur inequality aversion, i.e., envy and guilt, in a bargaining process, which I modeled as a loss of utility if receiving a smaller or a larger share of a surplus to be divided. In open-ended alternating-offer bargaining between two parties with similar time and inequality preferences, strongly guilt-perceiving bargainers gain utility from reducing an advantageous situation until the inequality between the bargainers is eliminated. Therefore, in the presence 
of sufficient guilt, the unique bargaining outcome is the immediate acceptance of an equal division.

In contrast, bilateral low guilt, ceteris paribus, can materially benefit the proposing bargainer. If the bargaining parties perceive guilt only to such an extend that their utility remains increasing in the own payoff despite increasing inequality, then the impact of guilt results in a more unequal division than predicted by Rubinstein (1982) for purely self-interest bargainers if $\alpha<\delta \beta$ (see appendix 6.2). Envy, ceteris paribus, reinforces the bargaining position of each bargainer, but only if guilt is low, because a non-credible threat of a non-envious bargainer to reject unequal contracts may become credible in the case with envy. The bargaining outcome is more equal than predicted by Rubinstein (1982) for purely self-interest bargainers if $\alpha>\delta \beta$.

For a low strength of guilt, the partial derivatives of the equilibrium partition imply that the equilibrium partition is increasing in the common strength of guilt and decreasing in the common discount factor and strength of envy. Envy has a stronger marginal impact on the equilibrium partition than guilt. The bargainers' individual envy, guilt and discounting have opposite effects on the equilibrium partition. The share of each bargainer in-/decreases in the strength of the own envy/guilt. Like in Rubinstein (1982)'s solution without inequality aversion, agreement is immediate and the higher a common discount factor, the more equal will be the agreed division. Taking the limits of the equilibrium partition for low guilt and envy shows that the equilibrium partition is between the equal division and one (see appendix 6.1). Inequality aversion with low guilt diminishes the utility each bargainer derives from his more equal bargaining outcome, even for the party that materially gains, in comparison to the utility that purely self-interested bargainers derive from the Rubinstein division. Yet, the second mover realizes a higher material payoff and utility level than a purely self-interested bargainer if bargainers are inequality aversion with high guilt and, thus, equal partition instead of the Rubinstein division is agreed (see appendix 6.3).

The condition $\alpha<\delta \beta$ is ruled out by Fehr \& Schmidt (1999)'s original model of inequality aversion that assumes $\beta \leq \alpha$, but this assumption may be relaxed to account for welfare concerns that can interact with concern for inequality aversion (see, Engelmann 2012; Kohler 2011).

In general, the bargaining of symmetrically inequality-averse bargainers is not equivalent to the bargaining of impatient purely self-interested bargainers, but the equilibrium partition can coincide with the Rubinstein division if the opposing effects of envy and guilt on the alternating-offer bargaining outcome just offset each other, i.e. $\alpha=\delta \beta$.

\section{Appendix}

\subsection{Partial derivatives and limits for low guilt}

If $\beta<0.5$, the equilibrium partition $p^{*}$ and its partial derivatives are given by: 


$$
\begin{aligned}
p^{*} & =\frac{\left(1+\alpha_{b}\right)\left(1+2 \alpha_{s}\right)-\delta_{b}\left(1+\alpha_{s}\right)+\delta_{b}\left(\beta_{b}+\beta_{s} \delta_{s}\left(1-2 \beta_{b}\right)\right)}{\left(1+2 \alpha_{b}\right)\left(1+2 \alpha_{s}\right)-\delta_{b} \delta_{s}\left(1-2 \beta_{b}\right)\left(1-2 \beta_{s}\right)}=\frac{1+\alpha-\beta \delta}{1+2 \alpha+\delta(1-2 \beta)}=: \frac{N}{D} \\
\frac{\partial p^{*}}{\partial \delta} & =-(1+\alpha-\beta) * D^{-2}<0 \\
\frac{\partial p^{*}}{\partial \delta_{s}} & =\delta_{b}(1-2 \beta)(1+\alpha-\beta)\left(1+2 \alpha-\delta_{b}(1-2 \beta)\right) * D^{-2} \geq 0 \\
\frac{\partial p^{*}}{\partial \delta_{b}} & =-(1+2 \alpha)(1+\alpha-\beta)\left(1+2 \alpha-\delta_{s}(1-2 \beta)\right) * D^{-2}<0 \\
\frac{\partial p^{*}}{\partial \alpha} & =-(1-\delta) * D^{-2}<0 \\
\frac{\partial p^{*}}{\partial \alpha_{s}} & =\delta(1-\delta)\left(1-2 \beta_{b}\right)\left(1+2 \alpha_{b}-\delta\left(1-2 \beta_{s}\right)\right) * D^{-2} \geq 0 \\
\frac{\partial p^{*}}{\partial \alpha_{b}} & =-(1-\delta)\left(1+2 \alpha_{s}\right)\left(1+2 \alpha_{s}-\delta\left(1-2 \beta_{b}\right)\right) * D^{-2}<0 \\
\frac{\partial p^{*}}{\partial \beta} & =-\delta \frac{\delta-1}{(2 \alpha+\delta-2 \beta \delta+1)^{2}}=\delta(1-\delta) * D^{-2} \geq 0 \\
\frac{\partial p^{*}}{\partial \beta_{s}} & =-\delta^{2}(1-\delta)\left(1-2 \beta_{b}\right)\left(1+2 \alpha_{s}-\delta\left(1-2 \beta_{b}\right)\right) * D^{-2} \leq 0 \\
\frac{\partial p^{*}}{\partial \beta_{b}} & =\delta(1-\delta)\left(1+2 \alpha_{s}\right)\left(1+2 \alpha_{b}-\delta\left(1-2 \beta_{s}\right)\right) \geq 0
\end{aligned}
$$

The respective signs follow from evaluating the derivatives. The limits of the equilibrium partition $p^{*}$ are given by $\lim _{\delta \rightarrow 0}=\frac{1+\alpha}{1+2 \alpha} \in[0.5,1], \lim _{\delta \rightarrow 1}=0.5, \lim _{\alpha \rightarrow 0}=\frac{1-\beta \delta}{1+\delta(1-2 \beta)} \in(0.5,1]$, $\lim _{\alpha \rightarrow \infty}=\frac{1+\alpha-\beta \delta}{1+2 \alpha+\delta(1-2 \beta)}=0.5, \lim _{\beta \rightarrow 0}=\frac{1+\alpha}{1+2 \alpha+\delta} \in[0.5,1]$ and $\lim _{\beta \rightarrow 0.5}=\frac{1+\alpha-0.5 \delta}{1+2 \alpha} \in[0.5,1]$. The limit values follow from evaluating the limits.

If $\beta<0.5$, the partition $p_{2}$ and its partial derivatives are given by:

$$
\begin{aligned}
p_{2}\left(p^{*}\right) & =\frac{\alpha+\delta(1-\beta)}{1+2 \alpha+\delta(1-2 \beta)}=: \frac{N}{D} \\
\frac{\partial p_{2}}{\partial \delta} & =(1+\alpha-\beta) * D^{-2}>0 \\
\frac{\partial p_{2}}{\partial \alpha} & =(1-\delta) * D^{-2}>0 \\
\frac{\partial p_{2}}{\partial \beta} & =-\delta(1-\delta) * D^{-2} \leq 0
\end{aligned}
$$

The respective signs follow from evaluating the derivatives. The limits of the partition $p_{2}$ are given by $\lim _{\delta \rightarrow 1}=0.5, \lim _{\alpha \rightarrow 0}=\frac{\delta(1-\beta)}{1+\delta(1-2 \beta)} \in[0,0.5), \lim _{\alpha \rightarrow \infty}=\frac{\alpha+\delta(1-\beta)}{1+2 \alpha+\delta(1-2 \beta)}=0.5$, $\lim _{\beta \rightarrow 0}=\frac{\alpha+\delta}{1+2 \alpha+\delta} \in[0,0.5]$ and $\lim _{\beta \rightarrow 0.5}=\frac{\alpha+0.5 \delta}{1+2 \alpha+\delta} \in[0,0.5]$. The limit values follow from evaluating the limits. 


\subsection{Rubinstein division versus equilibrium partition with inequality aversion}

If $\beta<0.5$, then envy and guilt determine if and how the equilibrium partition with inequality aversion deviates from the Rubinstein division:

$$
\begin{aligned}
\frac{1}{1+\delta} & \lesseqgtr \frac{1+\alpha-\beta \delta}{1+2 \alpha+\delta(1-2 \beta)} \\
\alpha & \lesseqgtr \beta \delta
\end{aligned}
$$

\subsection{Utility in the subgame perfect equilibrium with inequality aversion}

Irrespective of the strength of guilt, the utility of a guilt-perceiving seller, who perceives guilt in the equilibrium, is not higher than the utility of a purely self-interested seller that receives $\frac{1}{1+\delta}$ :

$$
\frac{u_{s}\left(p^{*}\right)}{\left.u_{s}\left(\frac{1}{1+\delta}\right)\right|_{\beta=0}}=\left\{\begin{array}{l}
\frac{(1+\delta)(1+\alpha-\beta)}{1+2 \alpha+\delta(1-2 \beta)} \in[0.5,1] \text { if } \beta<0.5 \\
\frac{1+\delta}{2} \in[0.5,1) \text { if } \beta \geq 0.5
\end{array}\right.
$$

The utility of a guilt-perceiving buyer, whose utility in equilibrium is unaffected by guilt, is not lower than the utility of a purely self-interested buyer if guilt is low and higher if guilt is high:

$$
\frac{u_{b}\left(p^{*}\right)}{\left.u_{b}\left(\frac{1}{1+\delta}\right)\right|_{\beta=0}}=\left\{\begin{array}{l}
\frac{(1+\delta)(1+\alpha-\beta)}{1+2 \alpha+\delta(1-2 \beta)} \in[0.5,1] \text { if } \beta<0.5 \\
\frac{1+\delta}{2 \delta} \in(1, \infty] \text { if } \beta \geq 0.5
\end{array}\right.
$$

\section{References}

Barr, A., Wallace, C., Ensminger, J., Henrich, J., Barrette, C., Bolyanatz, A., Cardenas, J.-C., Gurven, M., Gwako, E., Lesorogol, C., Marlowe, F., McElreath, R., Tracer, D., \& Ziker, J. (2009). Homo ÃEqualis: A cross-society experimental analysis of three bargaining games. University of Oxford, Department of Economics: Economics Series Working Papers 422.

Bellemare, C., Kröger, S., \& Van Soest, A. (2008). Measuring inequity aversion in a heterogeneous population using experimental decisions and subjective probabilities. Econometrica, 76, 815-839.

Bolton, G. E., \& Ockenfels, A. (2000). ERC: A theory of equity, reciprocity and competition. American Economic Review, 90, 166-193.

Camerer, C. F. (2003). Behavioral Game Theory. Experiments in Strategic Interaction. The roundtable series in behavioral economics. Princeton: Princeton University Press.

Cooper, D. J., \& Kagel, J. H. (n.d.). Other regarding preferences: A selective survey of experimental results. In J. H. Kagel, \& A. E. Roth (Eds.), Handbook of Experimental Economics, Volume 2. Princeton: Princeton University Press.

De Bruyn, A., \& Bolton, G. E. (2008). Estimating the influence of fairness on bargaining behavior. Management Science, 54, 1774-1791.

Engelmann, D. (2012). How not to extend models of inequality aversion. Journal of Economic Behavior E Organization, 81, 599-605.

Fehr, E., \& Schmidt, K. M. (1999). A theory of fairness, competition, and cooperation. Quarterly Journal of Economics, 114, 817-868. 
Goeree, J. K., \& Holt, C. A. (2000). Asymmetric inequality aversion and noisy behavior in alternating-offer bargaining games. European Economic Review, 44, 1079-1089.

Herreiner, D., \& Puppe, C. (2009). Envy freeness in experimental fair division problems. Theory and Decision, 67, 65-100.

Kohler, S. (2008). Inequality aversion and stochastic decision-making: Experimental evidence from Zimbabwean villages after land reform. In A. Innocenti, \& P. Sbriglia (Eds.), Games, Rationality and Behavior: Essays on Behavioral Game Theory and Experiments (pp. 63-100). Basingstoke: Palgrave McMillan.

Kohler, S. (2011). Altruism and fairness in experimental decisions. Journal of Economic Behavior $\mathcal{E}$ Organization, 80, 101-109.

Kohler, S. (2012a). Guilt causes equal or unequal division in alternating-offer bargaining. University Library of Munich, Germany: MPRA Paper 40760.

Kohler, S. (2012b). Incomplete information about social preferences explains equal division and delay in bargaining. Games, 3, 119-137.

Kohler, S. (2013a). Envy can promote more equal division in alternating-offer bargaining. Journal of Neuroscience, Psychology, and Economics, 6, 31-41.

Kohler, S. (2013b). More fair play in an ultimatum game after resettlement in Zimbabwe: A field experiment and a structural model. PloS one, 8, e64791.

Mauleon, A., \& Vannetelbosch, V. (2013). Relative concerns and delays in bargaining with private information. Games, 4, 329-338.

Montero, M. (2007). Inequity aversion may increase inequity. Economic Journal, 117, C192-C204.

Montero, M. (2008). Altruism, spite and competition in bargaining games. Theory and Decision, $65,125-151$.

Roth, A. E. (1985). A note on risk aversion in a perfect equilibrium model of bargaining. Econometrica, 53, 207.

Rubinstein, A. (1982). Perfect equilibrium in a bargaining model. Econometrica, 50, 97-109.

Shaked, A., \& Sutton, J. (1984). Involuntary unemployment as a perfect equilibrium in a bargaining model. Econometrica, 52, 1351-1364.

Smith, R. (Ed.) (2008). Envy: Theory and Research. New York: Oxford University Press.

Tan, J. H. W., \& Bolle, F. (2006). On the relative strengths of altruism and fairness. Theory and Decision, 60, 35-67.

Zwick, R., Rapoport, A., \& Howard, J. C. (1992). Two-person sequential bargaining behavior with exogenous breakdown. Theory and Decision, 32, 241-268. 